\title{
Wpływ kinesiotapingu na dolegliwości bólowe odcinka lędźwiowo-krzyżowego kręgosłupa
}

\section{The influence of kinesiotaping on lumbar spine pain}

\author{
Żaneta Ciosek', Łukasz Kopacz², Łukasz Samulak³, Agata Kaźmierczak³, Iwona Rotter \\ 1Samodzielna Pracownia Rehabilitacji Medycznej Pomorskiego Uniwersytetu Medycznego w Szczecinie \\ ul. Żołnierska 54, 71-210 Szczecin \\ Kierownik: dr n. med. Iwona Rotter
}

${ }^{2}$ Katedra i Zakład Propedeutyki i Fizykodiagnostyki Stomatologicznej Pomorskiego Uniwersytetu Medycznego w Szczecinie al. Powstańców Wlkp. 72, 70-111 Szczecin

Kierownik: dr n. med. Danuta Lietz-Kijak

${ }^{3}$ Studenckie Koło Naukowe przy Samodzielnej Pracowni Rehabilitacji Medycznej Pomorskiego Uniwersytetu Medycznego w Szczecinie Opiekun: dr n. med. Iwona Rotter

\section{SUMMARY}

Introduction: Pain in the lumbosacral spine is currently one of the most common pain complaints among the elderly. About $72 \%$ of the Polish population younger than 40 years have at least once been treated by a doctor for back pain. Degenerative changes of intervertebral joints, overloads, intervertebral disc diseases, and dysfunction of spinal ligaments are very often responsible for the formation of back pain, which is basically a problem of the elderly. Material and methods: The study was conducted among 60 residents of a Nursing Home in Szczecin with chronic lumbar pain.

The age range was 56-85 years. Subjects were randomly divided into two groups of 30 (study group, where KinesioTaping was used, and a control group without KinesioTaping application). To assess the degree of pain experienced by the patient a visual analogue scale (VAS) in the horizontal format from 0-10
\end{abstract}

was used, on which subjects scored the severity of pain. Flexion, extension, tilt and rotation were measured with a tape to assess spinal and trunk mobility.

Results: In all patients, who had a KinesioTaping patch applied on the lumbosacral spine pain measured by VAS reduced ( $p \leq 0.001$ ). Considering respondents' sex, the spine mobility in the tilting position improved in men in the study group in terms of tilting to both sides. In all patients, the application of a KinesioTaping patch significantly improved the rotation to the right side ( $\mathrm{p} \leq 0.05)$, scores in the "finger-floor" flexion test ( $p \leq 0.01)$, and the extension range ( $p \leq 0.01)$.

Conclusion: KinesioTaping is a beneficial method reducing pain and improving the mobility in the lumbosacral spine. The improvement was independent of the sex of the respondents. Key words: KinesioTaping, spine, pain.

\section{STRESZCZENIE}

Wstęp: Bóle kręgosłupa lędźwiowo-krzyżowego są obecnie jedną z najczęściej występujących dolegliwości bólowych wśród osób starszych. Za powstawanie bólów kręgosłupa bardzo często odpowiedzialne są zwyrodnienia, przeciążenia, choroby krążka międzykręgowego i osłabienie aparatu więzadłowego kręgosłupa. Materiał i metody: Badania zostały przeprowadzone wśród 60 pensjonariuszy Domu Pomocy Społecznej w Szczecinie z przewlekłymi dolegliwościami bólowymi odcinka lędźwiowo-krzyżowego. Przedział wiekowy wynosił 56-85 lat. W sposób losowy dokonano podziału na dwie 30-osobowe grupy (grupę badaną, gdzie została naklejona aplikacja KinesioTaping, oraz grupę kontrolną - bez aplikacji). Do oceny stopnia odczuwanego bólu użyto wizualno-analogowej skali VAS w formacie poziomej skali cyfrowej w zakresie 0-10, na której pensjonariusze zaznaczali natężenie odczuwanego bólu. $W$ badaniu ruchomości kręgosłupa i tułowia zmierzono za pomocą centymetra zgięcie, wyprost, nachylenie i rotację. Rozpatrując zakres ruchu nachylenia z uwzględnieniem płci badanych, można zauważyć, że poprawa nastąpiła u mężczyzn w grupie badanej w zakresie nachylenia w obie strony.

Wyniki: U wszystkich badanych, którym zaaplikowano KinesioTaping na okolicę lędźwiowo-krzyżową, nastąpiło zmniejszenie dolegliwości bólowych według skali VAS ( $\mathrm{p} \leq 0,001)$. Nastąpiła również istotna poprawa w zakresie: rotacji w prawą stronę $(\mathrm{p} \leq 0,05)$, zgięcia ocenianego testem „palec-podłoga” ( $\mathrm{p} \leq 0,01)$ i ruchu wyprostu $(p \leq 0,01)$. Nie odnotowano różnic istotnych statystycznie pomiędzy grupą badaną a grupą kontrolną. Wnioski: KinesioTaping jest korzystną metodą redukującą dolegliwości bólowe oraz wpływającą na poprawę zakresu ruchów kręgosłupa w odcinku lędźwiowo-krzyżowym u osób starszych. Słowa kluczowe: KinesioTaping, kręgosłup, ból.

\section{WSTĘP}

Bóle kręgosłupa lędźwiowo-krzyżowego są obecnie jedną z najczęściej występujących dolegliwości bólowych wśród osób starszych $[1,2]$. Z danych epidemiologicznych wynika, że dolegliwości bólowe kręgosłupa lędźwiowo-krzyżowego są obecnie problemem interdyscyplinarnym [3]. Schorzeniem tym zajmują się zróżnicowani specjaliści z dziedziny ortopedii, neurologii, reumatologii i fizjoterapii [4, 5]. Leczenie obejmuje również psychoterapię, farmakoterapię i edukację pacjenta [6]. 
Wydatek ponoszony przez państwo spowodowany leczeniem nieobecnością w pracy i rezygnacją z niej na poczet świadczeń wypłacanych z tytułu niezdolności do pracy sprawia, że ta kwestia staje się problemem nie tylko klinicznym, ale i społeczno-socjalnym.

Styl życia współczesnego człowieka przyczynia się do otyłości, ograniczenia wysiłku fizycznego, zmniejszenia siły mięśni (również tych odpowiedzialnych za stabilizację kręgosłupa), nieprzestrzegania zasad ergonomii pracy, braku dbałości o prawidłową postawę i higienę życia [7]. Oznacza to z reguły początek przewlekłych dolegliwości bólowych które wielokroć prowadzą do ograniczonej sprawności w czynnościach dnia codziennego [8]. Stosując się do wytycznych prawidłowego odpoczynku, przybieranych pozycji, ergonomii pracy, można uniknąć przeciążenia kręgosłupa. Nie wymaga to dużego nakładu pracy, a umożliwia prawidłowe funkcjonowanie [9]. Za powstawanie bólów kręgosłupa bardzo często odpowiedzialne są zwyrodnienia, które zasadniczo są problemem osób starszych, zmiany związane ze stawami międzykręgowymi, przeciążenia, choroby krążka międzykręgowego i osłabienie aparatu więzadłowego kręgosłupa [10]. Kluczowym celem terapii w dolegliwościach bólowych kręgosłupa jest dążenie do przywrócenia jak największego poziomu aktywności, a także przeciwdziałanie nawrotom przypadłości [11]. Zagadnienie odnoszące się do genezy powstawania bólu całego kręgosłupa, a także wdrożenie odpowiednich metod terapeutycznych efektywnych w walce z dolegliwościami bólowymi jest bardzo szerokim oraz interesującym zagadnieniem dla lekarzy i fizjoterapeutów.

Obecnie występuje różnorodność metod rehabilitacyjnych i zabiegów fizykalnych, które wykorzystywane są w leczeniu zespołów bólowych kręgosłupa lędźwiowo-krzyżowego. Dobór należytych technik i zabiegów powinien bazować na solidnym i dokładnym badaniu klinicznym. Jedną z przykładowych metod terapeutycznych w dolegliwościach bólowych odcinka lędźwiowo-krzyżowego jest „KinesioTaping”, który został wprowadzony na rynek w 1970 r. przez dr. Kenzo Kase. Metoda ta polega na oklejaniu wybranych partii ciała plastrami, które charakteryzują się specjalną, elastyczną strukturą. Działanie taśmy bazuje na regulacji napięcia mięśniowego w miejscu aplikacji, przez co zwiększa się zakres ruchu oraz siły mięśniowej [12].

Celem badań była ocena wpływu KinesioTapingu na dolegliwości bólowe odcinka lędźwiowo-krzyżowego kręgosłupa. Dodatkowym celem było określenie, czy zakres ruchu oraz dolegliwości bólowe pacjentów ulegają poprawie w zależności od płci.

\section{MATERIA $~ I$ METODY}

Badania zostały przeprowadzone wśród 60 pensjonariuszy Domu Pomocy Społecznej w Szczecinie z przewlekłymi dolegliwościami bólowymi odcinka lędźwiowo-krzyżowego. Przedział wiekowy wśród badanych wynosił 56-85 lat. W sposób losowy dokonano podziału na dwie 30-osobowe grupy. W grupie pierwszej (badanej) - 22 kobiety i 8 mężczyzn (poddanej aplikacji
KinesioTaping, ankiecie i badaniu ruchomości kręgosłupa oraz tułowia), w grupie drugiej (kontrolnej) - 21 kobiet i 9 mężczyzn (poddanej ankiecie oraz badaniu ruchomości kręgosłupa i tułowia). Badania były anonimowe i dobrowolne. Ankieta wraz z badaniem ruchomości kręgosłupa została przeprowadzona dwukrotnie - w 1. i 7. dniu badania. Grupa pierwsza została poddana leczeniu metodą KinesioTaping: zastosowano technikę powięziową zgodną z metodyką. Aplikację wykonywano w pozycji stojącej, w możliwie pełnym zgięciu tułowia. Plaster w kształcie litery „Y” został naklejony dokładnie w miejscu bolesności odcinka lędźwiowo-krzyżowego. Następnie pacjentów poinstruowano, aby bez zbędnej troski o plastry wykonywali wszystkie czynności dnia codziennego przez 7 dni.

W badaniu została użyta metoda sondażu diagnostycznego za pomocą kwestionariusza ankiety. Narzędzie składało się z 14 pytań zamkniętych w części I oraz 12 pytań zamkniętych w części II (8 w przypadku grupy kontrolnej) z możliwością wybrania jednej prawidłowej odpowiedzi. Do oceny stopnia odczuwanego bólu przez pensjonariusza użyto wizualno-analogowej skali VAS w formacie poziomej skali cyfrowej w zakresie 0-10 (0 - bez bólu, 10 - ból nie do wytrzymania), na której zaznaczono natężenie odczuwanego bólu. W badaniu ruchomości kręgosłupa i tułowia zmierzono za pomocą centymetra zgięcie, wyprost, nachylenie i rotację. Zgięcie zostało zmierzone w pozycji stojącej przy wyprostowanych stawach kolanowych. Po wykonaniu głębokiego skłonu w przód przez pensjonariusza, starającego się z wyprostowanymi kończynami górnymi dosięgnąć jak najbliżej stóp, zmierzona została odległość między końcami palców a podłogą. Pomiar wyprostu został wykonany w pozycji stojącej. Dłoniowa część ręki umieszczona była na tylnej stronie uda; po wykonaniu maksymalnego wyprostu została zmierzona odległość między końcem opuszki 3. palca a podłożem. Rotacja tułowia w lewą i prawą stronę została zmierzona od grzebienia biodrowego do wysokości wyrostka mieczykowatego mostka. Nachylenie tułowia w prawą i lewą stronę zmierzono analogicznie po obu stronach. Część dłoniowa ręki osoby badanej ułożona była na bocznej stronie uda, po maksymalnym nachyleniu tułowia w bok został dokonany pomiar odległości od opuszki 3. palca do podłoża [13].

Analizę statystyczną przeprowadzono w programie Statistica 10 PL. Oprócz statystyk opisowych (średnia arytmetyczna, odchylenie standardowe, minimum, maksimum), określono normalność rozkładu badanych parametrów za pomocą testu Shapiro-Wilka. Ponieważ większość mierzonych wartości wykazywała rozkład odbiegający od normalnego, do ich porównania zastosowano nieparametryczny test Wilcoxona w przypadku porównania wartości zakresu różnych rodzajów ruchu przed tapingiem (t1) i po tapingu (t2) oraz do porównania wartości skali VAS przed tapingiem (t1) oraz po tapingu (t2). W przypadku grupy kontrolnej zastosowano taki sam sposób analiz statystycznych. W celu sprawdzenia istotnych różnic między grupą kobiet i mężczyzn oraz grupą badaną i kontrolną zastosowano nieparametryczny test U Manna-Whitneya. Do przeprowadzenia wyżej wymienionych analiz statystycznych przyjęto poziom istotności dla $\mathrm{p}<0,05$. 


\section{WYNIKI}

W grupie badanej bez uwzględnienia podziału na płeć po aplikacji KinesioTapingu na odcinek lędźwiowo-krzyżowy kręgosłupa deklarowana wartość poziomu dolegliwości bólowych według skali VAS zmalała, a wynik jest wysoce istotny statystycznie $(\mathrm{p} \leq 0,001)$. Rozpatrując poprawę z uwzględnieniem płci, wystąpiła ona u kobiet w grupie badanej i była znacząco wysoka $(p \leq 0,001)$. W grupie badanej średnia wartość dolegliwości bólowych według skali VAS przed badaniem wynosiła $6,73( \pm 1,68)$, natomiast w grupie kontrolnej wynosiła ona 6,30 $( \pm 1,21)$. Podczas drugiego badania (po zdjęciu KinesioTapingu) średnia wartość dolegliwości bólowych w grupie badanej wynosiła 5,00 $( \pm 1,98)$, zaś w grupie kontrolnej 6,23 $( \pm 1,30)$ - tabela 1.

TABELA 1. Wartości skali VAS grupy badanej oraz grupy kontrolnej w trakcie pierwszego (T1) i drugiego (T2) badania

\begin{tabular}{|c|c|c|c|c|c|c|}
\hline \multirow{2}{*}{ Grupa } & \multicolumn{3}{|c|}{ VAS T1 } & \multicolumn{3}{|c|}{ VAS T2 } \\
\hline & $x$ & $\min$. & maks. & $x$ & $\min$. & maks. \\
\hline $\begin{array}{l}\text { Badana } \\
n=30\end{array}$ & $6,73 \pm 1,68$ & 3 & 10 & $\begin{array}{c}5,00 \pm 1,98 \\
* * * \text { VAS T1 } 1 \mathrm{~B}_{\mathrm{M}+\mathrm{K}}\end{array}$ & 1 & 8 \\
\hline $\begin{array}{l}\text { Kobiety } \\
n=22\end{array}$ & $6,73 \pm 1,93$ & 3 & 10 & $\begin{array}{r}4,77 \pm 2,18 \\
* * * \text { VAS T1 } 1 B_{K}\end{array}$ & 1 & 8 \\
\hline $\begin{array}{l}\text { Mężczyźni } \\
\mathrm{n}=8\end{array}$ & $6,75 \pm 0,71$ & 6 & 8 & $5,63 \pm 1,19$ & 4 & 8 \\
\hline $\begin{array}{l}\text { Kontrolna } \\
n=30\end{array}$ & $6,30 \pm 1,21$ & 5 & 8 & $6,23 \pm 1,30$ & 5 & 8 \\
\hline $\begin{array}{l}\text { Kobiety } \\
n=21\end{array}$ & $6,29 \pm 1,31$ & 5 & 8 & $6,29 \pm 1,31$ & 5 & 8 \\
\hline $\begin{array}{l}\text { Mężczyźni } \\
n=9\end{array}$ & $6,33 \pm 1,00$ & 5 & 7 & $6,11 \pm 1,36$ & 5 & 8 \\
\hline
\end{tabular}

Rozpatrując zakres ruchu nachylenia z uwzględnieniem płci badanych, zauważyć można, iż poprawa nastąpiła u mężczyzn w grupie badanej w zakresie nachylenia w obie strony ( $p \leq 0,05)$. W analizie całościowej bez uwzględnienia podziału na płeć zarówno w grupie badanej, jak i w grupie kontrolnej nie stwierdzono poprawy w zakresie nachylenia w prawo i lewo. W grupie badanej średnia wartość zakresu ruchu nachylenia w prawo przed badaniem wynosiła $45,00( \pm 6,40)$, a nachylenia w lewo $45,43( \pm 6,48)$. Podczas drugiego badania (po zdjęciu KinesioTapingu) średnia wartość zakresu w przypadku nachylenia w prawo wynosiła $44,60( \pm 6,42)$, natomiast przy nachyleniu w lewo 45,13 $( \pm 6,41)$ - tabela 2 .

U wszystkich badanych, którym zaaplikowano KinesioTaping na okolicę lędźwiowo-krzyżową, nastąpiła istotna poprawa w zakresie rotacji w prawą stronę ( $\mathrm{p} \leq 0,05)$. W grupie badanej średnia wartość zakresu rotacji w prawo przed badaniem wynosiła 6,60 $( \pm 2,24)$, a rotacji w lewo 6,80 $( \pm 2,27)$. Podczas drugiego badania (po zdjęciu KinesioTapingu) średnia wartość zakresu obu rotacji zwiększyła się. W przypadku rotacji w prawo wynosiła ona 7,07 $( \pm 2,77)$, natomiast rotacji w lewo 7,30 $( \pm 2,55)$.

W grupie badanej bez uwzględnienia podziału na płeć, podczas testu „palec-podłoga” w trakcie drugiego badania wystąpiła istotna statystycznie poprawa $(p \leq 0,01)$. W grupie kontrolnej nie odnotowano poprawy. W grupie badanej średnia wartość testu „palec-podłoga” przed badaniem wynosiła 13,20 $( \pm 16,43)$, natomiast w grupie kontrolnej $16,80( \pm 13,44)$. Podczas drugiego badania (po zdjęciu KinesioTapingu) średnia wartość testu „palec-podłoga” w grupie badanej wynosiła $11,97( \pm 15,18)$, zaś w grupie kontrolnej 16,80 $( \pm 13,47)$.

W grupie badanej bez uwzględnienia podziału na płeć zaszła poprawa istotna statystycznie w zakresie ruchu wyprostu $(\mathrm{p} \leq 0,01)$. Biorąc pod uwagę płeć, w grupie badanej poprawa zakresu ruchu wyprostu wystąpiła u mężczyzn ( $\mathrm{p} \leq 0,05)$. W grupie kontrolnej u kobiet $w$ trakcie obu badań wynik istotnie różnił się od wyników mężczyzn. W grupie badanej średnia wartość wyprostu tułowia przed badaniem wynosiła 13,20 $( \pm 16,43)$, natomiast w grupie kontrolnej wynosiła ona 16,80 $( \pm 13,44)$. Podczas drugiego badania średnia wartość wyprostu tułowia w grupie badanej wynosiła 11,97 $( \pm 15,18)$, zaś w grupie kontrolnej 16,80 $( \pm 13,47)$.

\section{DYSKUSJA}

Celem prowadzonych badań było sprawdzenie wpływu KinesioTapingu na dolegliwości bólowe odcinka lędźwiowo-krzyżowego wśród pensjonariuszy Domu Pomocy Społecznej w Szczecinie. Badania wykazały, że aplikacja KinesioTaping poprawiła zakres ruchomości kręgosłupa, tułowia, jak również zmniejszyła dolegliwości bólowe według skali VAS.

Podobne badania na temat wpływu KinesioTaping na dolegliwości bólowe odcinka lędźwiowo-krzyżowego zostały już przeprowadzone. Badanie takie przedstawili w 2011 r. Paoloni i wsp. [14]. W eksperymencie wzięło udział 39 kobiet i mężczyzn w wieku 30-80 lat z przewlekłym bólem kręgosłupa lędźwiowo-krzyżowego, u których ból utrzymywał się przez nie mniej niż 12 tyg. Do oceny bólu użyto skali VAS. Aby ocenić wpływ na mięśnie, zastosowano także aplikację sEMG, czyli badanie funkcji mięśni przez analizę impulsów elektrycznych wytwarzanych przez te mięśnie. Oprócz tego badani brali udział w 30-minutowych ćwiczeniach z terapeutą, 3 razy w tygodniu. Wyniki wskazują na znaczne obniżenie bólu po zastosowaniu aplikacji KinesioTaping, zmniejszenie napięcia mięśniowego oraz polepszenie funkcjonalności mięśni u wszystkich badanych.

Kolejny opis przypadku na ten sam temat został przeprowadzony przez Hwang-Bo i Lee [15]. Poddana badaniu została 36-letnia fizjoterapeutka mająca problem z przewlekłymi bólami odcinka lędźwiowo-krzyżowego kręgosłupa. Do oceny także zastosowano skalę VAS oraz ODQ. Aplikacja była utrzymywana przez 3 dni z rozciągnięciem sięgającym 130-140\%. Rezultat był następujący: w ciągu trzech dni ocena bólu z 8 punktów spadła aż do 2. Dzięki temu fizjoterapeutka bez dolegliwości bólowych wróciła do wykonywania zawodu.

Chen $i$ wsp. przeprowadzili podobne badania w 2012 r., z tym że korzystając z funkcjonalnego KinesioTapingu powięziowego [16]. Chciał on porównać tę metodę z tzw. efektem placebo, naklejając plaster bez żadnych wytycznych w miejsce bólu u pacjentów z bólami w odcinku lędźwiowo-krzyżowym kręgosłupa. 21 pacjentów otrzymało funkcjonalny KinesioTaping 
TABELA 2. Zakres ruchu nachylenia (prawa i lewa strona) grupy badanej oraz grupy kontrolnej w trakcie pierwszego (T1) i drugiego badania (T2)

\begin{tabular}{|c|c|c|c|c|c|c|c|c|c|c|c|c|}
\hline \multirow{2}{*}{ Grupa } & \multicolumn{3}{|c|}{ Nachylenie [P] T1 } & \multicolumn{3}{|c|}{ Nachylenie [L] T1 } & \multicolumn{3}{|c|}{ Nachylenie [P] T2 } & \multicolumn{3}{|c|}{ Nachylenie [L] T2 } \\
\hline & $x$ & $\min$. & maks. & $x$ & $\min$. & maks. & $\mathbf{x}$ & $\min$. & maks. & $x$ & $\min$. & maks. \\
\hline $\begin{array}{l}\text { Badana } \\
n=30\end{array}$ & $45,00 \pm 6,40$ & 25 & 56 & $45,43 \pm 6,48$ & 30 & 56 & $44,60 \pm 6,42$ & 25 & 55 & $45,13 \pm 6,41$ & 30 & 56 \\
\hline $\begin{array}{l}\text { Kobiety } \\
n=22\end{array}$ & $44,77 \pm 6,85$ & 25 & 56 & $44,95 \pm 6,60$ & 30 & 52 & $44,77 \pm 6,49$ & 25 & 55 & $45,05 \pm 6,26$ & 30 & 52 \\
\hline $\begin{array}{l}\text { Mężczyźni } \\
n=8\end{array}$ & $45,63 \pm 5,32$ & 40 & 55 & $46,75 \pm 6,36$ & 39 & 56 & $\begin{array}{c}44,13 \pm 6,62 \\
{ }^{*} \text { Nach[P]T1B }_{M}\end{array}$ & 35 & 55 & $\begin{array}{c}45,38 \pm 7,25 \\
*{ }^{*} \text { Nach[L]T1B } \\
\end{array}$ & 36 & 56 \\
\hline $\begin{array}{l}\text { Kontrolna } \\
\mathrm{n}=30\end{array}$ & $47,63 \pm 5,22$ & 40 & 55 & $47,47 \pm 6,36$ & 37 & 56 & $47,63 \pm 5,22$ & 40 & 55 & $47,60 \pm 6,30$ & 37 & 56 \\
\hline $\begin{array}{l}\text { Kobiety } \\
n=21\end{array}$ & $47,71 \pm 5,39$ & 42 & 55 & $46,86 \pm 6,51$ & 37 & 55 & $47,71 \pm 5,39$ & 42 & 55 & $46,86 \pm 6,51$ & 37 & 55 \\
\hline $\begin{array}{l}\text { Mężczyźni } \\
n=9\end{array}$ & $47,44 \pm 5,10$ & 40 & 53 & $48,89 \pm 6,09$ & 42 & 56 & $47,44 \pm 5,10$ & 40 & 53 & $49,33 \pm 5,75$ & 42 & 56 \\
\hline
\end{tabular}

TABELA 3. Zakres rotacji (w prawo i w lewo) grupy badanej i grupy kontrolnej podczas pierwszego badania (T1) oraz drugiego (T2)

\begin{tabular}{|c|c|c|c|c|c|c|c|c|c|c|c|c|}
\hline \multirow{2}{*}{ Grupa } & \multicolumn{3}{|c|}{ Rotacja [P] T1 } & \multicolumn{3}{|c|}{ Rotacja [L] T1 } & \multicolumn{3}{|c|}{ Rotacja [P] T2 } & \multicolumn{3}{|c|}{ Rotacja [L] T2 } \\
\hline & $x$ & $\min$. & maks. & $x$ & $\min$. & maks. & $\mathbf{x}$ & $\min$. & maks. & $x$ & $\min$. & maks. \\
\hline $\begin{array}{l}\text { Badana } \\
n=30\end{array}$ & $6,60 \pm 2,24$ & 2 & 10 & $6,80 \pm 2,27$ & 1 & 10 & $\begin{array}{c}\text { 7,07 } \pm 2,77 \\
* \operatorname{Rot}[\mathrm{P}] \mathrm{T} 1 \mathrm{~B}_{\mathrm{M}+\mathrm{K}}\end{array}$ & 2 & 13 & $7,30 \pm 2,55$ & 3 & 12 \\
\hline $\begin{array}{l}\text { Kobiety } \\
n=22\end{array}$ & $6,77 \pm 2,27$ & 2 & 10 & $6,86 \pm 2,38$ & 1 & 10 & $7,18 \pm 2,81$ & 2 & 13 & $7,41 \pm 2,48$ & 3 & 12 \\
\hline $\begin{array}{l}\text { Mężczyźni } \\
n=8\end{array}$ & $6,13 \pm 2,23$ & 3 & 9 & $6,63 \pm 2,07$ & 3 & 8 & $6,75 \pm 2,82$ & 3 & 10 & $7,00 \pm 2,88$ & 3 & 10 \\
\hline $\begin{array}{l}\text { Kontrolna } \\
n=30\end{array}$ & $5,80 \pm 2,43$ & 2 & 9 & $6,30 \pm 2,17$ & 2 & 9 & $5,87 \pm 2,39$ & 2 & 9 & $6,37 \pm 2,17$ & 2 & 9 \\
\hline $\begin{array}{l}\text { Kobiety } \\
n=21\end{array}$ & $6,00 \pm 2,68$ & 2 & 9 & $6,00 \pm 2,51$ & 2 & 9 & $6,00 \pm 2,68$ & 2 & 9 & $6,00 \pm 2,51$ & 2 & 9 \\
\hline $\begin{array}{l}\text { Mężczyźni } \\
n=9\end{array}$ & $5,33 \pm 1,73$ & 4 & 8 & $7,00 \pm 0,71$ & 6 & 8 & $5,56 \pm 1,59$ & 4 & 8 & $7,22 \pm 0,45$ & 7 & 8 \\
\hline
\end{tabular}

TABELA 4. Wyniki testu palec-podłoga grupy badanej i grupy kontrolnej w trakcie pierwszego badania (T1) i drugiego (T2)

\begin{tabular}{lcccccc}
\multirow{2}{*}{ Grupa } & \multicolumn{2}{c}{ Test palec-podłoga T1 } & \multicolumn{2}{c}{ Test palec-podłoga T2 } \\
\cline { 2 - 7 } & $\mathbf{x}$ & min. maks. & $\mathbf{x}$ & min. maks. \\
\hline $\begin{array}{l}\text { Badana } \\
\mathrm{n}=30\end{array}$ & $13,20 \pm 16,43$ & 0 & 62 & $\begin{array}{c}11,97 \pm 15,18 \\
\star * \text { Tpp }[\mathrm{T} 1] \mathrm{B}_{\mathrm{M}+\mathrm{K}}\end{array}$ & 0 & 60 \\
\hline $\begin{array}{l}\text { Kobiety } \\
\mathrm{n}=22\end{array}$ & $11,73 \pm 16,76$ & 0 & 62 & $11,23 \pm 16,07$ & 0 & 60 \\
\hline $\begin{array}{l}\text { Mężczyźni } \\
\mathrm{n}=8\end{array}$ & $17,25 \pm 15,84$ & 0 & 39 & $14,00 \pm 13,15$ & 0 & 33 \\
\hline $\begin{array}{l}\text { Kontrolna } \\
\mathrm{n}=30\end{array}$ & $16,80 \pm 13,44$ & 0 & 38 & $16,80 \pm 13,47$ & 0 & 38 \\
\hline $\begin{array}{l}\text { Kobiety } \\
\mathrm{n}=21\end{array}$ & $14,86 \pm 13,55$ & 0 & 31 & $14,86 \pm 13,55$ & 0 & 31 \\
\hline $\begin{array}{l}\text { Mężczyźni } \\
\mathrm{n}=9\end{array}$ & $21,33 \pm 12,76$ & 10 & 38 & $21,33 \pm 12,87$ & 10 & 38 \\
\hline
\end{tabular}

powięziowy, a 22 placebo KinesioTaping. U wszystkich zdiagnozowano ból w dolnej części pleców kręgosłupa. Badanie trwało 2 tyg. Grupa z aplikacją powięziową po 2 tyg. wykazała znacząco lepsze wyniki w redukcji bardzo mocnego bólu od grupy z aplikacją placebo. U osób ze średnim bólem nie odnotowano żadnej różnicy.

Interesujące badania zostały także przeprowadzone w Hiszpanii na Uniwersytecie Granada [17]. Zadano tam pytanie: czy KinesioTaping jest w stanie zmniejszyć niefunkcjonalność, ból
TABELA 5. Zakres wyprostu tułowia grupy badanej i grupy kontrolnej podczas pierwszego badania ( $\mathrm{T} 1$ ) oraz drugiego (T2)

\begin{tabular}{|c|c|c|c|c|c|c|}
\hline \multirow{2}{*}{ Grupa } & \multicolumn{3}{|c|}{ Wyprost T1 } & \multicolumn{3}{|c|}{ Wyprost T2 } \\
\hline & $x$ & $\min$. & maks. & $\mathbf{x}$ & $\min$. & maks. \\
\hline $\begin{array}{l}\text { Badana } \\
n=30\end{array}$ & $54,03 \pm 15,90$ & 0 & 69 & $\begin{array}{c}53,17 \pm 15,74 \\
* * W T 1 B_{M+K}\end{array}$ & 0 & 68 \\
\hline $\begin{array}{l}\text { Kobiety } \\
n=22\end{array}$ & $52,82 \pm 18,27$ & 0 & 69 & $52,41 \pm 18,11$ & 0 & 68 \\
\hline $\begin{array}{l}\text { Mężczyźni } \\
\mathrm{n}=8\end{array}$ & $57,38 \pm 5,39$ & 45 & 62 & $\begin{array}{c}55,25 \pm 5,97 \\
\text { *W T1B }\end{array}$ & 42 & 60 \\
\hline $\begin{array}{l}\text { Kontrolna } \\
n=30\end{array}$ & $59,77 \pm 2,285$ & 56 & 64 & $59,83 \pm 2,34$ & 56 & 64 \\
\hline $\begin{array}{l}\text { Kobiety } \\
n=21\end{array}$ & $\begin{array}{c}59,00 \pm 1,82 \\
{ }^{*} \mathrm{~W} T 1 \mathrm{~K}_{M}\end{array}$ & 56 & 62 & $\begin{array}{c}59,00 \pm 1,82 \\
\text { **W T2 } 2 K_{M}\end{array}$ & 56 & 62 \\
\hline $\begin{array}{l}\text { Mężczyźni } \\
\mathrm{n}=9\end{array}$ & $61,56 \pm 2,35$ & 58 & 64 & $61,78 \pm 2,33$ & 58 & 64 \\
\hline
\end{tabular}

oraz ograniczenie ruchomości u ludzi z przewlekłym, niespecyficznym bólem odcinka lędźwiowo-krzyżowego kręgosłupa. Udział w badaniu wzięło 60 dorosłych osób. Aplikację utrzymywano przez jeden tydzień. Ból ustępował stopniowo już w następnym dniu od naklejenia KinesioTapingu. Wyniki były zadowalające, u wszystkich badanych funkcjonalność kręgosłupa oraz jego ruchomość uległa poprawie. Efekt ten malał po 4 tyg. od zdjęcia aplikacji. Według autorów efekt okazał się zbyt mały, aby był klinicznie opłacalny. 
Do badań przystąpili również koreańscy autorzy Kim i wsp. [18], których celem była ocena skuteczności KinesioTapingu w zwalczaniu bólu dolnej części kręgosłupa. 43 ochotników, którzy byli pacjentami w szpitalu, wzięło udział w eksperymencie. Część z nich miała także aplikację placebo, która nie powinna przynieść żadnych pożądanych skutków. Po 3 dniach i sprawdzeniu zakresu bólu za pomocą skali VAS badający doszli do wniosku, iż KinesioTaping jest bardziej skuteczny od metody placebo, co potwierdzały wyniki badań.

Kontynuując badanie skuteczności działania przeciwbólowego metody KinesioTaping w 2013 r., aż 3 ośrodki przeprowadziły wspólne badania w tym temacie. Dwa z nich znajdują się w Sao Paulo, w Brazylii oraz jeden w Sydney, w Australii. $\mathrm{W}$ badaniach wzięło udział 148 pacjentów mających problem z niespecyficznymi bólami odcinka lędźwiowo-krzyżowego kręgosłupa. Celem pracy jest ocena skuteczności aplikacji w tradycyjnych planach rehabilitacyjnych stworzonych do pracy przez fizjoterapeutów wśród pacjentów z wyżej wymienioną jednostką chorobową. Leczenie ma trwać 5 tyg. (10 sesji rehabilitacyjnych). Niestety nie zostały one jeszcze ukończone [19].

\section{WNIOSKI}

KinesioTaping miał korzystny wpływ na zmniejszenie dolegliwości bólowych oraz poprawę zakres ruchów kręgosłupa w odcinku lędźwiowo-krzyżowym. Poprawa była niezależna od płci badanych.

\section{PIŚMIENNICTWO}

1. Bojczuk T., Przysada G., Strzępek Ł.: Wpływ ćwiczeń leczniczych na wskaźniki jakości życia u pacjentów z bólem dolnego odcinka kręgosłupa. Prz Med Uniw Rzesz. 2010, 1, 66-72.

2. Kwolek A., Korab D., Majka M.: Rehabilitacja w zespołach bólowych dolnego odcinka kręgosłupa - zasady postępowania. Post Rehab. 2004, 18 (3), 27-31.
3. Tancred B., Tancred G.: Implementation of exercise programmes for prevention and treatment of low back pain. Physiotherapy. 1996, 82 (3), 168-173.

4. MacEvilly M., Buggy D.: Back pain and pregnancy: a review. Pain. 1996, 64 (3), 405-414.

5. Schramm D.M., Grabois M.: How exercise helps patients with chronic pain. Phys Sports Med. 1997, 25 (4), 24.

6. Dziak A.: Komentarz do „Zaleceń stosowania fizjoterapii u pacjentów z bólami krzyża" wydanych przez Holenderskie Królewskie Towarzystwo Fizjoterapii. Rehab Med. 2004, 8, 28-30.

7. Sous M., Stryła W:: Ocena gibkości kręgosłupa chorych z zespołami bólów części lędźwiowej kręgosłupa na tle przepukliny jądra miażdżystego. Post Rehab. 1999, 13 (3), 45-55.

8. Kiwerski J.E.: Problem bólów krzyża u młodzieży. Post Rehab. 2001, 15 (2), 11-15.

9. Dziak A.: Dysfunkcje bólowe dolnego odcinka kręgosłupa lędźwiowego. Med Sportiva. 2005, 9 (4), 23-43.

10. Kwolek A., Korab D., Majka M.: Rehabilitacja w zespołach bólowych dolnego odcinka kręgosłupa - zasady postępowania. Post Rehab. 2004, 18 (3), 27-31.

11. Holenderskie Królewskie Towarzystwo Fizjoterapii: Zalecenia stosowania fizjoterapii u pacjentów z bólami krzyża. Rehab Med. 2004, 8, 6-26.

12. Kase K., Wallis J., Kase T.: Clinical therapeutic applications of the Kinesiotaping Method. Kinesio Taping Association, 2003, 2-5.

13. Zembaty A.: Kinezyterapia. Wyd. „Kasper” Sp. z o.o., Kraków 2003, 152-157.

14. Paoloni M., Bernetti A., Fratocchi G., Mangone M., Parrinello L., Cooper M. et al.: Kiensio Taping applied to lumbar muscles influences clinical and electromyographic characteristics in chronic low back pain patients. Eur J Phys Rehab Med. 2011, 2 (47), 237-244.

15. Hwang-Bo G., Lee J.H.: Effects of kinesio taping in a physical therapist with acute low back pain due to patient handling: a case report. Int J Occup Med Environ Health. 2011, 24 (3), 320-323.

16. Chen S.M., Alexander R., Kai Lo S., CookJ.: Effects of functional fascial taping on pain and function in patients with non-specific low back pain: a pilot randomized controlled trial. Clin Rehabil. 2012, 26 (10), 924-933.

17. Castro-Sanchez A.M., Lara-Palomo I.C., Mataran-Penarrocha G.A., Fernandez-Sanchez M., Sanchez-Labraca N.. Arroyo-Morales M.: Kinesio Taping reduces disability and pain slightly in chronic non-specific low back pain: a randomized trial. J Physiother. 2010, 58 (2), 89-95.

18. Kim C.H., Kim A.R., Kim S.H., Yoo H.J., Lee S.H.: The efficacy of Kinesio Taping in patients with low back pain. Korean Acad Fam Med. 2002, 2 (23), 197-204.

19. Added M.A., Costa L.O., Fukuda T.Y., Freitas D., Salomao E., Monteiro E. et al.: Efficacy of adding the kinesio taping method to guideline-endorsed conventional physiotherapy in patients with chronic nonspecific low back pain: a randomised controlled trial. BMC Musculoskeletal Disorders. $2013,14,301$. 